\title{
From CuAdernos de ECONOMÍA TO LATIN AMERICAN JOURNAL OF ECONOMICS
}

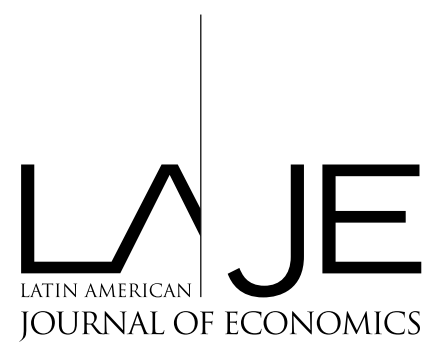

Published since the early 1960s, Cuadernos de Economía has been one the most successful outlets for economic research in the region. With over 800 original articles published and more than 500 article downloads every month through RePEc, the journal is indexed in Econlit, Scielo, BOWKER, HARPI and OCENET.

Initially, Cuadernos focused on the problems of developing economies, with research ranging from trade policies, stabilization programs, and financial crises. Over time, however, the journal has expanded its scope to almost every field in the profession: game theory, finance, econometrics, decision theory, and so on, while retaining an emphasis on empirical research.

Until 1992, all of the articles were published only in Spanish. That year, the journal became bilingual by publishing two articles in English, by William Easterly and Stanley Fischer.

In 1999, the editorial board decided to change the name to acknowledge the broader scope of the journal by adding "Latin American Journal of Economics" as a subtitle.

With the advent of the Internet, technological opportunities to improve our reach and dissemination increased substantially. Cuadernos de Economía took advantage of this new medium to grant open access to its entire collection of articles in PDF format both through its website and through Scielo.org.

Today, after almost 50 years of continued publication, The Latin American Journal of Economics is a mature outlet enjoying worldwide prestige, in large part due to the greater distribution provided by the Internet. For instance, nowadays many more abstract views and downloads occur for the English articles than those in Spanish. As a consequence, the editiorial board of the journal has decided publish solely in English, which has become the official language of the profession. We hope this change will make the published articles available to a much wider audience, improving dissemination and citability. 
A corollary of this editorial change is a modification of the title, to simply Latin American Journal of Economics (LAJE), dropping the original Cuadernos de Economía. Also, the journal's URL is changing from www. cuadernosdeeconomia.cl to www.laje-ce.org.

To mark this transformation, we will also be launching a series of research initiatives aimed at delivering a significant scientific production to be channeled through LAJE. The first of these is the conference on Two Centuries of Economic Growth: Latin America at its Bicentennial Celebration (see conference announcement at the end of this issue, advertisements section).

We hope you will enjoy what we have in store for you at LAJE, a traditional journal for Latin America evolving to meet the demands of a new era. 